\title{
Diferença de classe no SUS: efetivando a norma constitucional de acesso universal ao Sistema
}

\section{Claudio Balduino Souto Franzen ${ }^{1}$}

A discussão sobre a chamada diferença de classe na internação hospitalar do SUS prende-se a dois pontos polêmicos: à vedação à internação pelo SUS em acomodações superiores, pagando, o paciente, pela respectiva diferença pelas acomodações e pelos honorários médicos; e à triagem prévia em posto de saúde, antes da internação hospitalar pelo SUS, sendo vedado ao paciente ser atendido pelo médico de sua confiança.

Os argumentos utilizados pelos críticos à diferença de classe é de que essa sistemática implica em criar um SUS de $1^{\text {a }}$ classe e um SUS de $2^{\underline{a}}$ classe, quebrando o princípio da isonomia, além de violar o princípio da universalidade previsto na Constituição Federal de 1988.

Esses argumentos não passam de uma falácia, ou seja, de um raciocínio errado com aparência de verdadeiro. Na lógica e na retórica, a falácia é qualificada como um argumento logicamente inconsistente, sem fundamento, inválido ou falho na tentativa de provar eficazmente o que alega. Trata-se de um argumento que se destina à persuasão, e que, numa primeira análise, pode parecer convincente para grande parte do público, mas que, na essência, é insubsistente.

Inicialmente, cumpre rememorar que a chamada diferença de classe era possível antes da Constituição Federal de 1988, até que o antigo INAMPS editou uma Portaria, proibindo-a. Posteriormente, o Ministério da Saúde publicou uma resolução mantendo a proibição no âmbito do SUS, impedindo o acesso à chamada diferença de classe.

Necessário pontuar, a esse respeito, que até fazia sentido a proibição à diferenciação de classe no âmbito do INAMPS, que, a rigor, era uma seguradora, tanto que seus beneficiários eram chamados de segurados. Logo, até era defensável impedir que o optante de determinado plano de seguro pretendesse alterá-lo posteriormente, mediante

1 Médico. Conselho Regional de Medicina do Rio Grande do Sul. Porto Alegre, Brasil. E-mail: secdiretoria@cremers.org.br 
pagamento de uma complementação. Mas no âmbito do SUS, nos moldes em que está definido o acesso à saúde pela Carta da República de 1988, notadamente como direito de todos, a restrição afigura-se manifestamente inconstitucional.

Com efeito, da mesma maneira que ocorria anteriormente, o SUS não admite que paciente atendido inicialmente por seu médico busque internar-se diretamente pelo SUS, obrigando-o a procurar um posto de saúde, para uma 'triagem'. Assim agindo, o Poder Público viola o direito do paciente, criando-Ihe, por mera burocracia, embaraço ao pronto acesso aos serviços de saúde, além de desafirmar o seu direito sagrado de procurar o médico de sua confiança.

Veja-se que o paciente, da forma como vêm sendo aplicadas as normas do SUS, é cerceado em sua liberdade de escolha da maneira como quer (e pode) ser tratado. Além disso, esse mesmo paciente, tendo procurado um médico que, ao examiná-lo, entendeu devesse ocorrer baixa hospitalar, não vê a solicitação de baixa deferida, sem que tenha que se submeter a uma 'triagem' em posto de saúde. Novo cerceamento, pois, viola o direito que é o de ter a liberdade de escolha do médico de sua confiança, aquele com quem formou a relação médico-paciente, base milenar do atendimento médico em todo mundo civilizado, desde as regras de Hipócrates.

Por outro lado, o médico também vem sendo cerceado. Vê desaparecer sua autonomia, porque sua recomendação de baixa condiciona-se ao 'crivo' de outro médico, de um posto de saúde, que pode não ter a confiança do paciente.

Mas não somente isso.

Mesmo quando é atendido por médico cadastrado no SUS, se a primeira consulta é feita em caráter particular, para procedimentos diversos da consulta, tais como exames complementares e cirurgias, o paciente tem de passar por nova avaliação de outros médicos no posto de saúde.

Diante desses procedimentos meramente burocráticos, pois instituídos para facilitar o trabalho dos funcionários, sem preocupação com as dificuldades do doente, termina por se romper a relação médico-paciente, tão necessária para o sucesso do tratamento.

Essa nova rotina criada pelo Poder Público, acrescida à da proibição de opção por acomodações diferenciadas para os doentes que têm condições de pagar por diferença de classe, importou em retrocesso significativo, pois além do benefício pessoal ao paciente, o 
pagamento complementar pela diferença ajudava as instituições hospitalares e os médicos a compensar as perdas impostas pelo SUS e liberava mais leitos nas enfermarias.

A legitimidade da diferença de classe decorre puramente da aplicação do art. 196 da Constituição Federal: "A saúde é direito de todos e dever do Estado, garantido mediante políticas sociais e econômicas que visem à redução do risco de doenças e de outros agravos e ao acesso universal igualitário, às ações e serviços para sua promoção, proteção e recuperação" (BRASIL, 1988, p.131). Além desse direito constitucionalmente garantido à saúde, relembra-se que a criação do SUS - Sistema Único de Saúde destinou-se a um atendimento universal, a ser executado diretamente pelo poder público ou por pessoa física ou jurídica de direito privado (art. 197 da CF), para cuja consecução estabelecia determinações - gize-se até hoje não cumpridas de forma devida - no sentido de alocação de verbas, em todos os níveis do estado (União, Estados e Municípios), que permitiriam o financiamento desse sistema, que pela sua universalidade é efetivamente único no mundo.

O dispositivo honrava o compromisso que o Brasil assumiu ao tratar na Carta de 88 dos Princípios Fundamentais da República, que constituiu o Estado Democrático de Direito (art. $1^{\circ}$ ). Já ali, dentre outros, apontava o texto para a dignidade da pessoa humana (inciso III). Em seguida, a Constituição alude no art. 3ํa aos objetivos da República, colocando expressamente entre eles o de promover o bem de todos (inc. IV). Culminou o legislador constituinte em estabelecer que os direitos fundamentais são de todos, e garantidos a brasileiros e estrangeiros residentes no país (art. 5ํ).

Em face desses dispositivos constitucionais, o STF já havia firmado o entendimento quanto à legitimidade da diferença de classe, argumentando que "O direito à saúde, como está assegurado no art. 196 da Constituição, não deve sofrer embaraços impostos por autoridades administrativas, no sentido de reduzi-lo ou de dificultar o acesso a ele. Inexistência no caso de ofensa à isonomia”. Essa citação é retirada de dois acórdãos diferentes, mas sobre o mesmo tema, um da lavra do ilustre Ministro Moreira Alves (RE 261.268/RS) e outro do ilustre Ministro Ilmar Galvão (RE 226.835/RS), em decisões unânimes, que serviram como decisões paradigmas a balizar os acórdãos posteriores.

Foi justamente em função dessas decisões que reconheciam o acesso à saúde pelo SUS como direito de todos (em ações individuais), que o Conselho Regional de Medicina do Estado do Rio Grande do Sul, ante o reiterado descumprimento destas determinações 
pelo Estado e pelos municípios (em que a gestão do SUS se fazia na modalidade plena), resolveu ingressar com ações civis públicas, para que a população como um todo fosse beneficiada.

Os gestores cumpriam exclusivamente as decisões em casos individuais (quando o direito era reconhecido pelo Tribunal de Justiça do Estado do Rio Grande do Sul e pelo colendo Supremo Tribunal Federal), mas mantinham o deplorável entendimento de que a diferenciação de classe não deveria ser estendida a todos, desconhecendo o que a mais alta Corte do País sinalizava como claramente inconstitucional.

Ou seja, busca-se, na essência, fazer com que as autoridades administrativas cumpram as decisões do STF em relação a todos.

Recentemente, importante destacar o caso do Município de Giruá, em que o eminente Ministro Celso de Mello, julgando o Recurso Extraordinário n. 596.445, interposto por esta autarquia, acompanhou precedente deste Pretório Excelso, transcrevendo ementa do Recurso Extraordinário ํㅜㄹ 261.268/RS.

$\mathrm{Na}$ decisão proferida, o llustre Relator, Min. Celso de Mello, aponta, ainda, outros precedentes, como se verifica do decisum, in verbis:

Cumpre ressaltar, por necessário, que esse entendimento vem sendo observado em sucessivos julgamentos, proferidos no âmbito desta Corte, a propósito de questão essencialmente idêntica à que ora se examina nesta sede recursal (RE 228.750/RS, Rel. Min. Sepúlveda Pertence - RE 496.244/RS, Rel. Min. Eros Grau - RE 601.712/RS, Rel. Min. Carlos Britto RE 603.855/RS, Rel. Min. Cármen Lúcia, v.g.).

O exame da presente causa evidencia que o acórdão ora impugnado diverge da diretriz jurisprudencial que esta Suprema Corte firmou na matéria em referência.

Sendo assim, considerando as razões expostas, conheço e dou provimento ao presente recurso extraordinário (CPC, art. 557, § 1--A).

(Rextra 596.445/RS. STF. Rel. Min. Celso de Mello. Julgado em 18/12/2009. Publicado em 10/02/2010)

Além deste decisório, podemos citar precedente da lavra da ilustre Ministra Cármen Lúcia, no Recurso Extraordinário n. 603855, de origem em ação civil pública proposta pelo CREMERS, quando se entendeu que:

4. A matéria foi objeto de julgados do Supremo Tribunal, que concluiu pela prevalência da tese defendida pela Recorrente. Por isso a ele assiste razão, na forma do direito vigente. 5. A jurisprudência do Supremo Tribunal Federal firmou-se no sentido da possibilidade da internação hospitalar na modalidade "diferença de classe" sem ônus para o Estado. Essa faculdade conferida ao 
paciente atende ao mandamento constitucional que estabelece a saúde como direito de todos e dever do Estado.

Por fim, destaca-se outro precedente do STF, de autoria do Ministro Ayres Britto, também proveniente de ação civil pública interposta pelo CREMERS (Recurso Extraordinário n. 611559/RS), quando se entendeu que:

2. Pois bem, a parte recorrente sustenta violação ao art. 196 da Magna Carta de 1988.

3. Tenho que a insurgência merece acolhida. É que o entendimento do Tribunal de origem destoa da jurisprudência desta nossa Corte. Vejam-se, nesse mesmo sentido, os REs 226.835, da relatoria do ministro Ilmar Galvão; 228.750, da relatoria do ministro Sepúlveda Pertence; 496.244, da relatoria do ministro Eros Grau; e 261.268, da relatoria do ministro Moreira Alves, este com a seguinte ementa:

“Direito à saúde. 'Diferença de classe' sem ônus para o SUS. Resolução n. 283 do extinto INAMPS. Artigo 196 da Constituição Federal. - Competência da Justiça Estadual, porque a direção do SUS, sendo única e descentralizada em cada esfera de governo (art. 198, I, da Constituição), cabe, no âmbito dos Estados, às respectivas Secretarias de Saúde ou órgão equivalente. - O direito à saúde, como está assegurado no artigo 196 da Constituição, não deve sofrer embaraços impostos por autoridades administrativas no sentido de reduzi-lo ou de dificultar o acesso a ele. Inexistência, no caso, de ofensa à isonomia. Recurso extraordinário não conhecido.

Verifica-se, portanto, que é entendimento uníssono do Supremo Tribunal Federal pela inconstitucionalidade da vedação à internação pelo SUS em acomodações superiores, pagando, o paciente, a diferença pelas acomodações e pelos honorários médicos, tendo em vista que nenhum prejuízo é causado ao Sistema Único de Saúde.

A decisão no processo movido contra o Município de Giruá, a União e o Estado do Rio Grande do Sul determinou, ainda, que é inconstitucional impor aos pacientes a 'triagem prévia' em posto de saúde, antes de internação hospitalar pelo SUS, podendo o paciente ser diretamente internado, conforme prescrição do médico de sua confiança, e ser atendido por este durante a internação.

As alegações do Estado e dos Municípios réus das ações restringem-se a de que o SUS, mediante ato administrativo do Ministério da Saúde, proíbe a chamada diferença de classe, como o fez o antigo INAMPS em resolução, porque admiti-la seria quebrar a igualdade de tratamento (isonomia). 
Pois bem, as reiteradas decisões do STF são no sentido de que, sendo o atendimento universal pelo SUS um direito de todos, não pode mero ato administrativo reduzir ou dificultar o acesso a ele. E esse direito à saúde não deve servir de mera retórica, tornando o comando constitucional uma norma vazia de fundamento.

Ao contrário, a Constituição Federal deve ser lida no sentido de que é garantido um atendimento de todos; mas o serviço de saúde a ser oferecido pelo SUS deve ser adequado, de modo que o art. 196 da CF/1988 seja efetivo.

O STF decidiu sempre que os 'embaraços impostos por autoridades administrativas (leia-se gestores)' eram exatamente a resolução do INAMPS e a portaria, que proibiam a diferença de classe. As autoridades em questão, mesmo ante todos os precedentes da mais alta Corte do País, preferiam cumprir as decisões nas ações individuais, mantendo a ilegalidade quanto aos demais. As ações do CREMERS visaram justamente a fazer com que as autoridades administrativas cumprissem as decisões do STF em relação a todos, neste Estado.

Queriam (ou querem) tais autoridades fazer prevalecer o comportamento infelizmente tão comum na administração pública brasileira de cumprir os mandamentos legais 'apenas no que interessa'. Tais autoridades leem o art. 196 da CF de forma diferente (e errada) daquela que faz o Supremo Tribunal Federal, que, dentro do sistema democrático em que vivemos, decide as questões relativas à interpretação da Constituição. Ou seja, não compreendem que o dispositivo citado tenha criado ou garantido um direito (efetivo e adequado) a todos e sim que apenas teria estabelecido uma espécie de norma programática, pela qual o Estado, em todos os seus níveis, deveria se esforçar para atingir a meta.

O STF, porém, mostrou que a leitura correta é a de que o dispositivo estabelece um direito a todos, e que para garantir o exercício desse direito, o Estado deve criar políticas sociais e econômicas.

Dessa forma, a Portaria do INAMPS, anterior a Carta de 88, era incompatível com a atual Constituição, pois embaraçava o exercício do direito. De igual modo, a Resolução do SUS, que é posterior, sofre do mesmo vício de inconstitucionalidade.

Da mesma maneira que o STF reconhece que, se é um direito, todos podem exercê-lo, o que implica no dever do SUS arcar com as despesas que teria que suportar de qualquer forma, também reconhece que no exercício desse direito não há quebra da 
isonomia (igualdade de atendimento), que é outro argumento amiúde utilizado. Com efeito, o que a Corte estabeleceu é que se o direito é de todos, ao exercê-lo ninguém está quebrando com a regra da igualdade - todos o exercem da mesma maneira.

Assim, se alguém tem direito a que o SUS pague as despesas de internação e honorários médicos, o gestor deve promover 0 atendimento. Exerce-se 0 direito de maneira universal e igualitária. A diferença está em que aquela pessoa que tenha condições e possa pagar, negocie com o prestador de serviço (hospital) e com o médico um atendimento em outras acomodações e por um valor de honorários maior, arcando o SUS unicamente com o que teria de suportar de qualquer forma. De igual sorte, o atendimento aos outros pacientes, que não tem condições, seguirá da forma oferecida pelo SUS, já que o direito é de todos e a todos deve ser garantido.

É evidente que, se o atendimento se der em hospital público, cujo atendimento é única e exclusivamente pelo SUS, não será possível a busca dessa diferença. No entanto, e isso é quase que uma peculiaridade do Estado do Rio Grande do Sul, ao contrário da maioria das outras unidades da Federação, o atendimento em sua maior percentagem não se dá em hospitais públicos e sim em conveniados em geral (santas casas ou filantrópicos), em que uma parte se dá por atendimento do SUS e outra tem disponibilidade de leitos diferentes. Só aí tem cabimento a invocação da diferença, para pagamento conforme acerto.

Estima-se que, em média, $60 \%$ destes leitos se destinem ao SUS e $40 \%$ a outras modalidades de internação. É justamente sobre esta última parcela que se aplica a diferença de classe, sem furar filas, sem criar um SUS de $1^{\underline{a}}$ ou $2^{\underline{a}}$ classe, sem quebrar a isonomia. Os leitos do SUS continuarão sendo destinados exclusivamente ao SUS, que pagará exatamente o que já deveria pagar aos médicos e hospitais.

As internações pela diferença de classe voltam-se para os $40 \%$ restantes de leitos que já não eram destinados ao SUS, de qualquer maneira - razão pela qual não há qualquer prejuízo ao sistema imposto pelo constituinte. Ao contrário, além do benefício pessoal e direto ao paciente, o pagamento complementar decorrente da 'diferença de classe' ajuda as instituições hospitalares e os médicos a compensar as perdas impostas pelo SUS, pois é negociado um valor pela chamada diferença, além de liberar mais leitos nas enfermarias. 
De fato, a diferença de classe é um alento aos hospitais conveniados ao SUS que muito sofrem com o pagamento desproporcional. Como exemplo, vide tabelas abaixo, em que a diferença entre os custos de tratamentos deficitários cirúrgicos, clínicos, UTI e ambulatoriais e a tabela SUS é gritante (Tabelas 1 e 2):

Dados do Tribunal de Contas da União divulgados recentemente em rede nacional informam que foram desativados 123 mil leitos em todo o país, de 2010 até este ano. Portanto, admitir o pagamento adicional pela acomodação poderia permitir uma melhora das condições dos hospitais conveniados com o SUS. Essa situação precária do SUS não decorre da falta de médicos, nem da falta propriamente de recursos financeiros à disposição do Ministério da Saúde. No ano de 2013, dos R 9,4 bilhões de que o Ministério da Saúde dispunha para investir no SUS, foi repassado apenas $R \$ 3,9$ bilhões, ou seja, $40 \%$ do total disponível.

Não discordo, em tese, da política do Ministério da Saúde de priorizar o atendimento ambulatorial pelo SUS. Entretanto, a situação real do Brasil é outra. As doenças continuarão existindo e a necessidade de internação e cirurgias, também. Com o sistema vigente, o paciente leva, por vezes, dois a três meses para ser atendido em ambulatório e, depois, dois a três anos para obter uma intervenção cirúrgica ou uma consulta pelo SUS.

O SUS real não é o SUS idealizado.

O acesso universal à saúde é direito do cidadão. Não pode ser cerceado por medidas administrativas. A rede (de hospitais filantrópicos e particulares) não pode ser sucateada para defender teses ideológicas desprovidas de comprovação prática.

Por fim, além da diferença de classe servir como uma espécie de válvula de escape para os hospitais conveniados ao SUS, em situação precaríssima do ponto de vista financeiro, é sempre importante destacar que esse mecanismo preserva a relação médicopaciente, ao permitir que o paciente possa ser internado diretamente a pedido de seu médico, sem que se torne obrigatória a passagem por posto de saúde ou emergência, acabando com aquela situação constrangedora de a pessoa acabar sendo atendida por médico que lhe é absolutamente estranho.

A diferença de classe não inviabiliza o SUS, como pretendem alguns críticos, e sim faz com que se torne efetiva a norma constitucional de acesso universal ao SUS. 
Tabela 1) Exemplos de tratamentos deficitários: cirúrgicos, clínicos e em UTI (Dados de 2010)

\begin{tabular}{l|r|r|r|r}
\hline \multirow{2}{*}{ Tratamentos } & \multicolumn{1}{c|}{ Custo } & \multicolumn{2}{c|}{ Tabela } & \multicolumn{2}{c}{ Resultado } \\
\cline { 2 - 5 } & \multicolumn{1}{c}{$\mathrm{R} \$$} & $\mathrm{R} \$$ & $\mathrm{R} \$$ & \multicolumn{1}{c}{$\%$} \\
\hline Insuficiência respiratória aguda & $4.571,85$ & 480,87 & $(4.090,98)$ & $-850,7$ \\
\hline Pneumopatias agudas & $2.869,40$ & 582,42 & $(2.286,98)$ & $-392,7$ \\
\hline Colecistectomia por vídeo & $1.884,66$ & 693,05 & $(1.191,61)$ & $-171,9$ \\
\hline Apendicectomia & $1.769,60$ & 414,62 & $(1.354,98)$ & $-326,8$ \\
\hline Toractomia com drenagem fechada & $6.586,16$ & $1.029,44$ & $(5.556,72)$ & $-539,8$ \\
\hline Herniorrafia inguinal (unilateral) & $1.709,77$ & 426,02 & $(1.283,75)$ & $-301,3$ \\
\hline Diária de UTI - III & $1.311,31$ & 508,63 & $(802,68)$ & $-157,8$ \\
\hline
\end{tabular}

Fonte: Centro de Custos Irmandade da Santa Casa de Misericórdia de Porto Alegre.

Tabela 2) Exemplos de tratamentos ambulatoriais deficitários (Dados de 2010)

\begin{tabular}{l|r|r|r|r}
\hline \multirow{2}{*}{ Atendimentos em Ambulatório } & \multicolumn{1}{|c|}{ Custo } & \multicolumn{2}{c}{ Tabela } & \multicolumn{2}{c}{ Resultado } \\
\cline { 2 - 5 } & \multicolumn{1}{|c|}{$\mathrm{R} \$$} & $\mathrm{R} \$$ & $\mathrm{R} \$$ & \multicolumn{1}{c}{$\%$} \\
\hline Consulta básica adulto (PAB) & 28,79 & 2,04 & $(26,75)$ & $-1311,4$ \\
\hline Consulta básica pediátrica (PAB) & 17,10 & 2,04 & $(15,06)$ & $-738,4$ \\
\hline Consulta em especialidade adulto & 28,79 & 10,00 & $(18,79)$ & $-187,9$ \\
\hline Consulta em especialidade pediátrica & 17,10 & 10,00 & $(7,10)$ & $-71,0$ \\
\hline Emergência adulto & 279,73 & 12,47 & $(267,26)$ & $-2143,3$ \\
\hline Emergência obstétrica & 58,36 & 12,47 & $(45,89)$ & $-368,0$ \\
\hline Urgência/emergência pediátrica & 80,87 & 12,47 & $(68,40)$ & $-548,5$ \\
\hline Raio-X simples (Tórax PA, Lateral) & 26,02 & 6,88 & $(19,14)$ & $-278,2$ \\
\hline Ultrassonografia ginecológica & 34,05 & 24,20 & $(9,85)$ & $-40,7$ \\
\hline Ultrassonografia abdominal total & 45,34 & 37,95 & $(7,39)$ & $-19,5$ \\
\hline Endoscopia - EDA com sedação & 201,09 & 63,31 & $(137,78)$ & $-217,6$ \\
\hline
\end{tabular}

Fonte: Centro de Custos Irmandade da Santa Casa de Misericórdia de Porto Alegre.

\section{Referências bibliográficas}

BRASIL. Constituição (1988). Constituição da República Federativa do Brasil. Brasília, DF: Senado Federal, 2008.

BRASIL. Lei $n . .9 .080$, de 19 de setembro de 1990. Dispõe sobre as condições para a promoção, proteção e recuperação da saúde, a organização e o funcionamento dos serviços correspondentes e dá outras providências. Brasília, DF, 19 set. 1990. Disponível em: http://www.planalto.gov.br/ccivil 03/leis//8080.htm Acesso em: 10 de nov. 2014. 